\title{
Hydrogen Cyanamide Advances Pecan Budbreak and Harvesting
}

\author{
Bruce W. Wood \\ Southeastern Fruit and Tree Nut Research Laboratory, Agricultural research Service, U.S. Department \\ of Agriculture, P.O. Box 87, Byron, GA 31008
}

Additional index words. breeding, budbreak, dormancy, flowering, nuts, phenology, pollination, ripening

\begin{abstract}
Dormant season sprays of hydrogen cyanamide applied to pecan [Carya illinoinensis (Wangenh.) K. Koch] trees advanced budbreak, flowering, and shuck dehiscence. Hydrogen cyanamide was applied to dormant branches at $\approx 60$, 45, 30 , and 15 days before normal vegetative budbreak at rates of $0,120,240,480$, and $960 \mathrm{~mm}$ (corresponding to $\approx 0 \%, 0.5 \%$, $1 \%, 2 \%$, and $4 \%$, solutions for 3 years). Depending on treatment, hydrogen cyanamide advanced budbreak by as much as 17 days, female and male flower maturity by up to 15 days, and nut ripening by as much as 14 days without reducing nut yield or causing phytotoxicity. Hydrogen cyanamide applied at 480 to $960 \mathrm{mM} \approx 60$ days before expected budbreak possibly may be used commercially to advance ripening, manipulate time of pollen dispersal, and substitute for chilling when pecan is grown in mild environments.
\end{abstract}

The phenological characteristics of most commercial pecan cultivars cause several production and marketing problems (Wood et al., 1990). For example, nuts of most commercial pecan cultivars ripen late in the growing season. This is a problem because the major market for pecan is during Thanksgiving and Christmas (Mizelle and Westbury, 1985); accordingly, prices decline as the holiday season progresses (Fig. 1). Since pecan harvest is perilously close to this period, a means of advancing harvest would be useful. Another disadvantage of late season ripening is the likelihood of major economic losses due to the influence of rain on nut quality. Additionally, economic losses also occur due to flowering characteristics that lead to either insufficient pollination or excessive self-pollination (Marquard, 1988; Wood and Marquard, 1992). Advancing pecan flowering could increase the degree of complementary flowering and therefore increase nut yields.

Flowering date can be altered by rest-breaking chemicals such as $\mathrm{KNO}_{3}$, 4,6-dinitro-o-cresol, thiourea, oils, gibberellins, cytokinins, and cyanamides. Among these, hydrogen cyanamide (acid cyanamide or $\mathrm{H}_{2} \mathrm{CN}_{2}$ ) has effectively altered the phenology of deciduous crops (Erez, 1987; Shulman et al., 1986) such as kiwi (Actinidia chinensis Planch.) (Linsley-Noakes, 1989), grapes (Vitis vinifera L.) (George et al., 1988; Zelleke and Kliewer, 1989), raspberry (Rubus idaeus L.) (Snir, 1983, 1988), nectarines [Prunus persica (L.) Batsch.] (George and Nissen, 1988), cherry (Prunus avium L.) (Snir and Erez, 1988), and pistachio (Pistacia vera L.) (Pontikis, 1989). This study reports the responsiveness of pecan to a P-stabilized commercial formulation of hydrogen cyanamide (Dormex; SKW Trostberg AG, Germany) and demonstrates that it can be used to advance important phenological events and may solve harvesting- and flowering-related problems.

\section{Materials and Methods}

The response of pecan to hydrogen cyanamide was evaluated using 7-year-old 'Cheyenne' trees growing in an orchard at Byron,

Received for publication 14 Jan. 1993. Accepted for publication 23 Apr. 1993. We gratefully acknowledge SKW Trostberg AG of Germany for its generous donation of Dormex. Mention of a trademark or proprietary product does not constitute a guarantee or warranty of the produce by the U.S. Dept. of Agriculture and does not imply its approval to the exclusion of other products that may also be suitable. The cost of publishing this paper was defrayed in part by the payment of page charges. Under postal regulations, this paper therefore must be hereby marked advertisement solely to indicate this fact.
Ga. Trees were sprayed with hydrogen cyanamide before budbreak for 4 years.

Initially, trees were evaluated to determine the phytotoxicity of and the relative response of trees to hydrogen cyanamide at
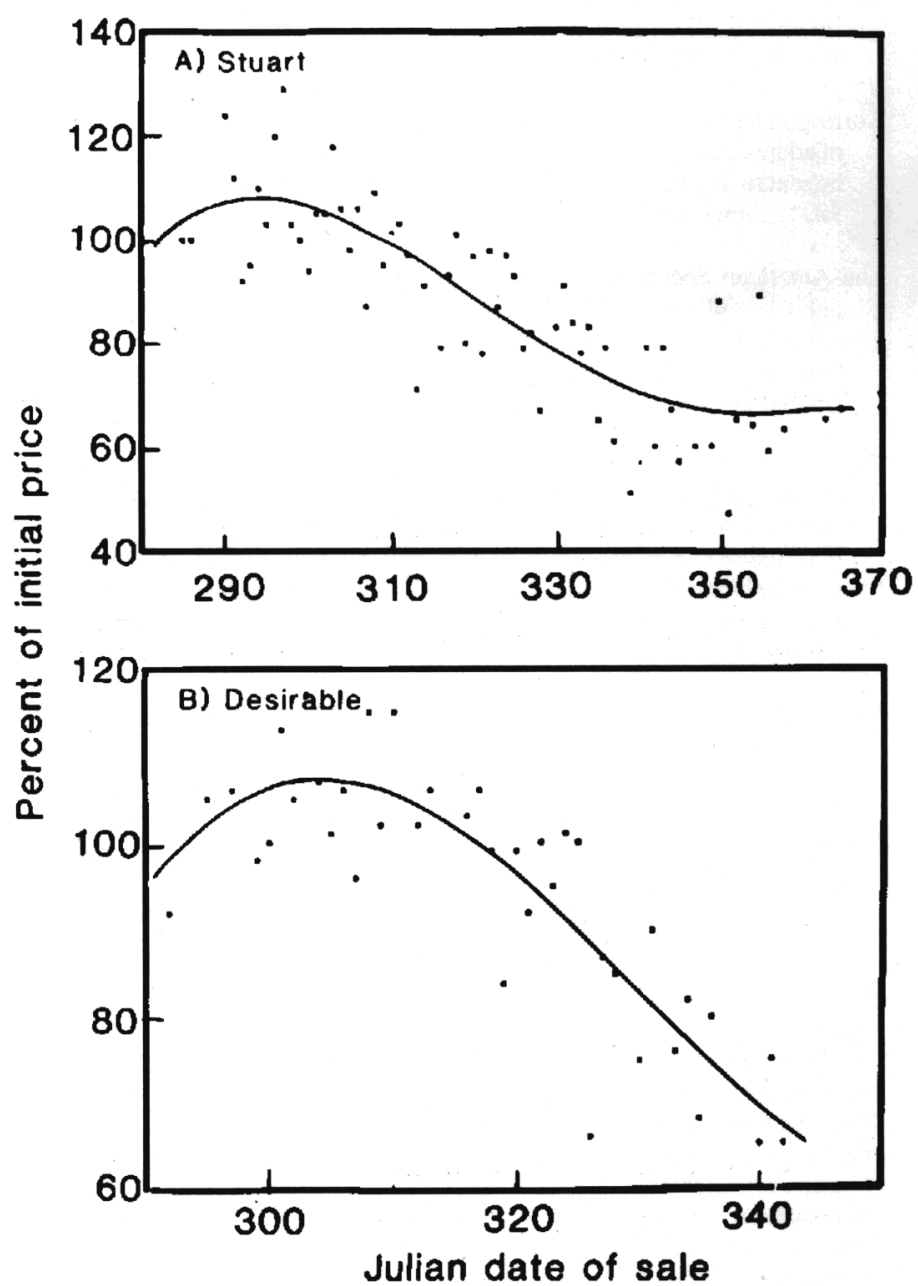

Fig. 1. Influence of date of sale on average wholesale price received for 'Desirable' and 'Stuart' pecans marketed in Georgia from 1976 to 1990 . Best-fit polynomial regressions areas follows: for 'Desirable', $\mathrm{y}=\left(\mathrm{a}+\mathrm{bx}+\mathrm{cx}^{2}+\mathrm{cx}^{3}\right), r^{2}=0.75$, where $a=(-24034) . b=222, c=(-0.68), d=0.0007$; for 'Stuart', $y=\left(a+b x+c x^{2}+d x^{3}\right)$, $\mathrm{r}^{2}=0.70$, where $\mathrm{a}=(-12809), \mathrm{b}=121.9, \mathrm{c}=(-0.38), \mathrm{d}=1.5, \mathrm{e}=(-0.0004)$. 
different times during dormancy. This was done by applying various concentrations of hydrogen cyanamide at 960, 1440, 1920, 2100,3600 , or $4800 \mathrm{~mm}$ with a wetting agent $(0.25 \%$ Surfel; Rhone Poulenc, Williamston, N.C.) $\approx 60$ days before anticipated budbreak. This was done on major limbs with four single-tree replicates. Trees were monitored for phytotoxicity until full leaf expansion.

Timing was estimated using $480 \mathrm{mM}$ hydrogen cyanamide sprays (with wetting agent) on major limbs at two week intervals from mid-December to mid-March. Five major limbs were treated on each date and trees were evaluated for budbreak.

Influence on budbreak. Hydrogen cyanamide was applied as a spray to the limb and shoot surfaces of the entire dormant tree at $\approx 60,45,30$, and 15 days before average pecan budbreak at the test location (1 Apr.). Since budbreak (identified as date when $90 \%$ of buds exhibits inner bud-scale split) varied from year to year, the relationship of application date to budbreak differed each of the three springs of the study. Hydrogen cyanamide was applied with a hand sprayer to the entire limb-shoot surface until well wetted at rates of $120,240,480$, and $960 \mathrm{mM}[\approx 0.5 \%, 1 \%, 2 \%$, and $4 \%$ solutions (by weight)] within $1 \mathrm{~h}$ after mixing with water $(\mathrm{pH} 6.5)$. A wetting agent at $0.25 \%$ was added to enhance wetting and absorption. An unsprayed control and wetting-agent checks were also included. The experiment was a completely randomized design consisting of five replicates comprised of 24 treatments (four spray dates $\times$ six spray treatments), with the experimental unit being a single tree; thus, the study used 120 trees. Trees were treated in Winters 1988-89, 1989-90, and 1990-91.

Trees were evaluated each year for budbreak (date of $90 \%$ inner bud-scale split), pollen shed (date when $50 \%$ of catkins had shed pollen), nut ripening (date when $90 \%$ of fruit had split shucks), nut quality (percentage of kernel), and nut production (kilograms of nuts produced per tree). Data were analyzed with the SAS statistical system (SAS Institute, Cary, N.C.) using a random coefficient model (Gumpertz and Pantula 1989). Trees were observed for phytotoxicity, alterations in tree form, shoot abortion, nut development, and abnormalities in kernel quality related to color. The possibility of residual activity was evaluated by visually assessing treated trees the growing season after the conclusion of the 3-year study.

\section{Results}

Budbreak. Hydrogen cyanamide induced early budbreak in pecan without apparent phytotoxicity if applied at $\leq 1920 \mathrm{mM}(8 \%$ solution). Rates of $2400 \mathrm{~mm}$ killed the terminal 2 to $4 \mathrm{~cm}$ of shoot tips, while higher rates killed the entire treated area, regardless of wood age. While budbreak was advanced with treatments of 960 $\mathrm{mM}$ from 30 to $90+$ days before normal budbreak, the optimum application tune was in January (Fig. 2), even though the late fall treatment (10 Dec.) influenced bud dormancy. Hydrogen cyanamide induced young 'Cheyenne' trees to break bud 17 to 34 days earlier, depending on concentration and application date, than trees in the checks or control treatments (Figs. 2 and 3). Wetting agent had no detectable influence on budbreak. There was also a significant rate $\mathrm{x}$ application-date interaction (Table 1). Hydrogen cyanamide applications $\approx 15$ and 30 days before budbreak, regardless of concentration, did not substantially influence date of budbreak, however, there was a substantial curvilinear response when applied 33 to 60 days before budbreak (Fig. 3). In addition to budbreak, there was a proportional advancement of leaf development, although this was not quantified. The effect of hydrogen cyanamide on budbreak varied with treatment year (Fig. 3), presumably as a result of different conditions each year.
Pollen shed. Hydrogen cyanamide treatments advanced the date of $50 \%$ pollen shed, making it nearly directly proportional to the advance of budbreak (Fig. 4). There was no indication of deleterious treatment effects on catkin formation, pollen maturation, viability (as tested by crossing), or stigmatic characteristics.

Fruit ripening. Fruit ripening date, as measured by shuck dehiscence, was also advanced by hydrogen cyanamide treatments (Table 1, Fig. 5). Rate and application date interacted and varied with treatment year. Applications from 45 to 60 days before budbreak advanced ripening by 10 to 14 days, depending on year. Applications within 30 days of budbreak did not advance ripening. In general, the 480 and $960 \mathrm{~mm}$ treatments were about equally effective and were significantly more effective than the $240 \mathrm{mM}$ treatment. The advancement of ripening was proportional to ad-

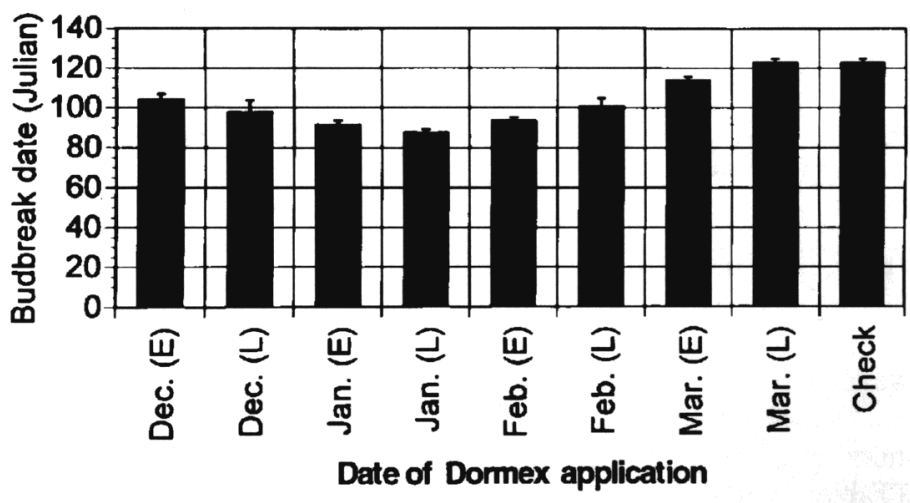

Fig. 2. Julian date of pecan budbreak in relation to hydrogen cyanamide (Dormex) application time $(480 \mathrm{mM}) . \mathrm{E}=$ application during the first half and $\mathrm{L}=$ application during the last half of the months.

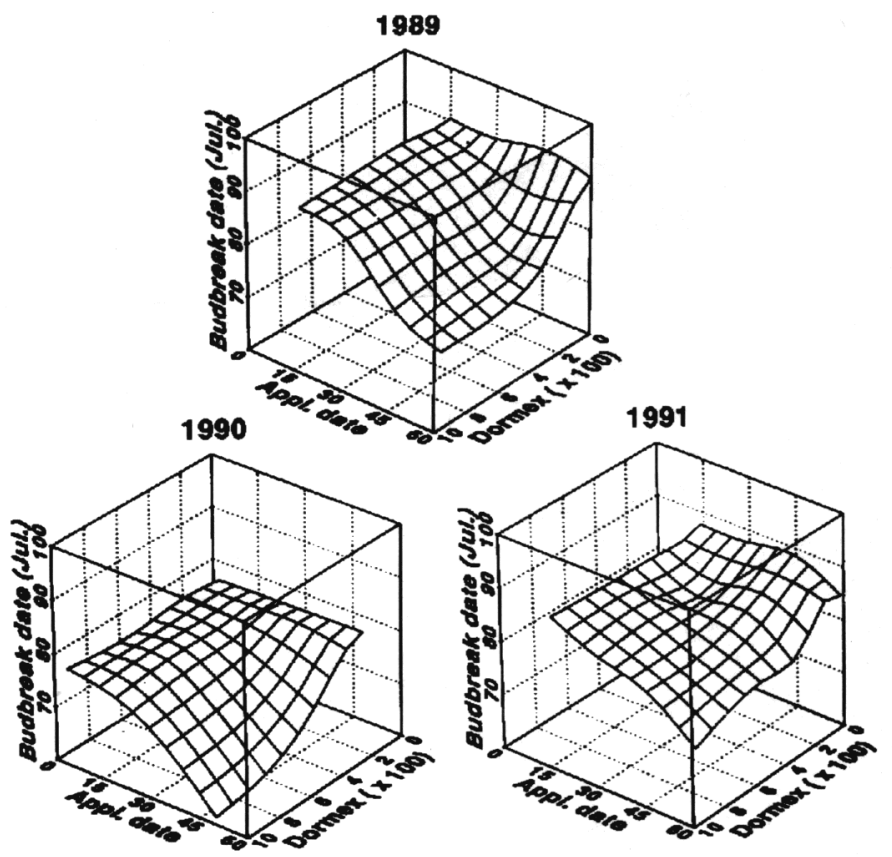

Fig. 3. Effect of prebudbreak treatments of hydrogen cyanamide (Dormex) on budbreak of young 'Cheyenne' pecan trees when applied before natural budbreak. Results are for three growing seasons (1989-91) and the response surface is a best-fit spline curve. The best-fit polynomial regression equations (where $\mathrm{y}=$ Julian date of budbreak and $\mathrm{x}=\mathrm{mM}$ rate of hydrogen cyanamide) for the earliest prebudbreak treatment date areas follows: for 1989, at -60 days, $y=\left(a+b x+c x^{3}\right)$, $r^{2}=0.99$, where $\mathrm{a}=90, \mathrm{~b}=(-0.04), \mathrm{c}=2.07^{\mathrm{e}-8}$; for 1990, at -48 days, $\mathrm{y}=(\mathrm{a}+\mathrm{bx}$ $\left.+\mathrm{cx}^{2}\right), r^{2}=0.98$, where $\mathrm{a}=78, \mathrm{~b}=(-0.03), \mathrm{c}=1.6^{\mathrm{e}-5}$; for 1991 , at -59 days, $\mathrm{y}=$ $\left(\mathrm{a}+\mathrm{bx}+\mathrm{cx}^{2}\right), r^{2}=0.97$, where $\mathrm{a}=87, \mathrm{~b}=(-0.03), \mathrm{c}=1.5^{\mathrm{e}-5}$. 
Table 1. Analysis of variance for budbreak, pollen shed, and shuck dehiscence characteristics of young trees treated with hydrogen cyanamide (Dormex). ${ }^{\mathrm{Z}}$

\begin{tabular}{|c|c|c|c|c|c|c|c|c|c|c|}
\hline \multirow[b]{2}{*}{ Effect } & \multirow[b]{2}{*}{ df } & \multicolumn{3}{|c|}{ Budbreak } & \multicolumn{3}{|c|}{ Pollen-shed } & \multicolumn{3}{|c|}{ Shuck dehiscence } \\
\hline & & $\begin{array}{l}\text { Mean } \\
\text { square }\end{array}$ & $\mathrm{F}$ & $P>\mathrm{F}$ & $\begin{array}{l}\text { Mean } \\
\text { square }\end{array}$ & $\mathrm{F}$ & $P>\mathrm{F}$ & $\begin{array}{l}\text { Mean } \\
\text { square }\end{array}$ & $\mathrm{F}$ & $P>\mathrm{F}$ \\
\hline & & & & 1989 & & & & & & \\
\hline Rate (R) & 4 & 210 & 45 & 0.001 & 43 & 64 & 0.001 & 33 & 6 & 0.004 \\
\hline Application date (AD) & 3 & 569 & 140 & 0.001 & 75 & 114 & 0.001 & 67 & 12 & 0.001 \\
\hline $\mathrm{R} \times \mathrm{AD}$ & 9 & 38 & 9 & 0.001 & 9 & 13 & 0.001 & 13 & 2 & 0.145 \\
\hline Error & 83 & 5 & --- & 1990 & 0.8 & --- & --- & 5 & --- & --- \\
\hline $\mathrm{R}$ & 4 & 156 & 53 & 0.001 & 111 & 21 & 0.001 & 84 & 27 & 0.001 \\
\hline $\mathrm{AD}$ & 3 & 345 & 100 & 0.001 & 728 & 116 & 0.001 & 34 & 11 & 0.001 \\
\hline $\mathrm{R} \times \mathrm{AD}$ & 9 & 49 & 14 & 0.001 & 66 & 11 & 0.001 & 20 & 6 & 0.001 \\
\hline Error & 83 & 3 & --- & 1991 & 5 & --- & --- & 3 & --- & --- \\
\hline $\mathrm{R}$ & 4 & 148 & 66 & 0.001 & 94 & 110 & 0.001 & 82 & 30 & 0.001 \\
\hline $\mathrm{AD}$ & 3 & 186 & 186 & 0.001 & 96 & 109 & 0.001 & 40 & 15 & 0.001 \\
\hline $\mathrm{R} \times \mathrm{AD}$ & 9 & 24 & 24 & 0.001 & 13 & 14 & 0.001 & 14 & 5 & 0.001 \\
\hline Error & 77 & 2 & --- & --- & 0.8 & --- & --- & 3 & --- & --- \\
\hline
\end{tabular}

Dormant pecan trees were treated with hydrogen cyanamide (at 0, 120, 240, 480, and $960 \mathrm{mM}$ ) at $\approx 60,45,30$, and 15 days before anticipated budbreak (1 Apr.).

vancement of budbreak, but was not 1: 1 .

Yield. Hydrogen cyanamide had no detectable influence on the number of nuts per tree, fill (percentage kernel), or nut volume (Table 2). Based on visual observations, the advancement of
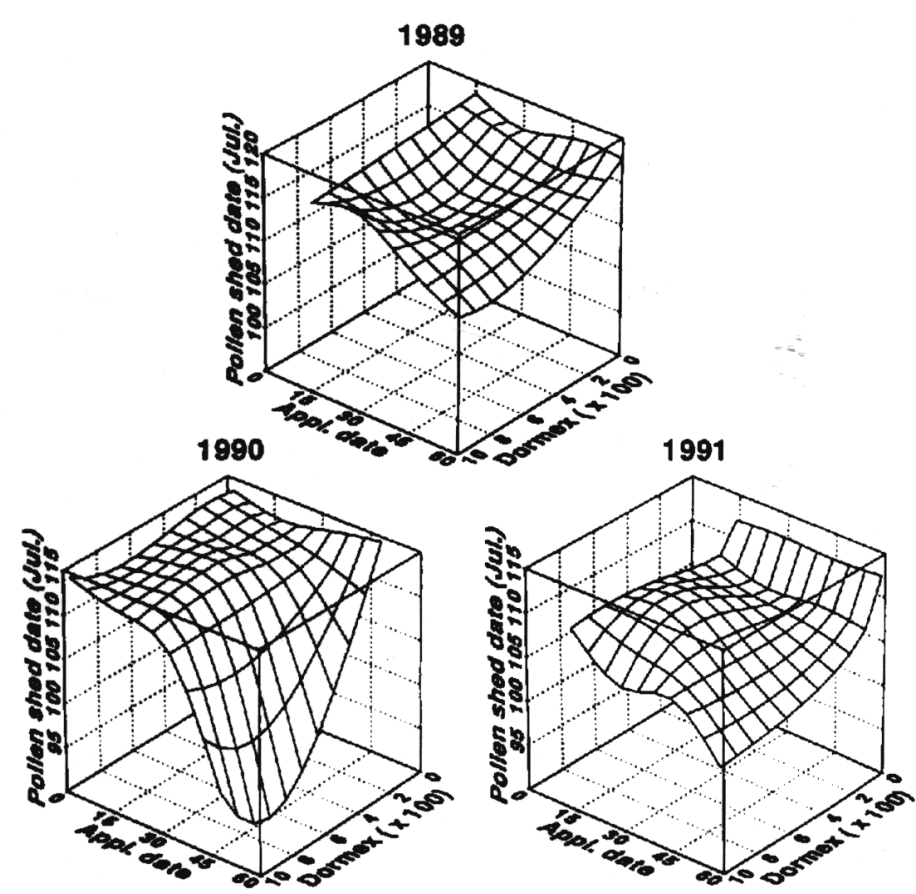

Fig. 4. Effect of hydrogen cyanamide (Dormex) on date of pollen shed of young 'Cheyenne' pecan trees. Results are for three growing seasons (1989-91) and the response surface is a best-fit spline curve. The best-fit polynomial regression equations (where $y=$ Julian date of pollen shed and $x=m M$ rate of hydrogen cyanamide) for the earliest prebudbreak application date for each year of study is as follows: for 1989, at -60 days, $\mathrm{y}=\left(\mathrm{a}+\mathrm{bx}+\mathrm{cx}^{3}\right), r^{2}=0.99$, where $\mathrm{a}=118$, $\mathrm{b}=(-0.014), \mathrm{c}=6.5^{\mathrm{e}-9} ;$ for 1990 , at -48 days, $\mathrm{y}=\left(\mathrm{a}+\mathrm{bx}+\mathrm{cx}^{3}\right), r^{2}=0.98$, where $\mathrm{a}=114, \mathrm{~b}=(-0.05), \mathrm{c}=3.2^{\mathrm{e}-8}$; for 1991 , at -59 days, $\mathrm{y}=[\mathrm{a}+\mathrm{bx}+\operatorname{csqrt}(\mathrm{x})], r^{2}=$ 0.99 , where $\mathrm{a}=1 i 2, \mathrm{~b}=0.008, \mathrm{c}=(-0.59)$. ripening by hydrogen cyanamide had no deleterious influence kernel color, although the earliest ripening treatment seemed to be a lighter color than the control.

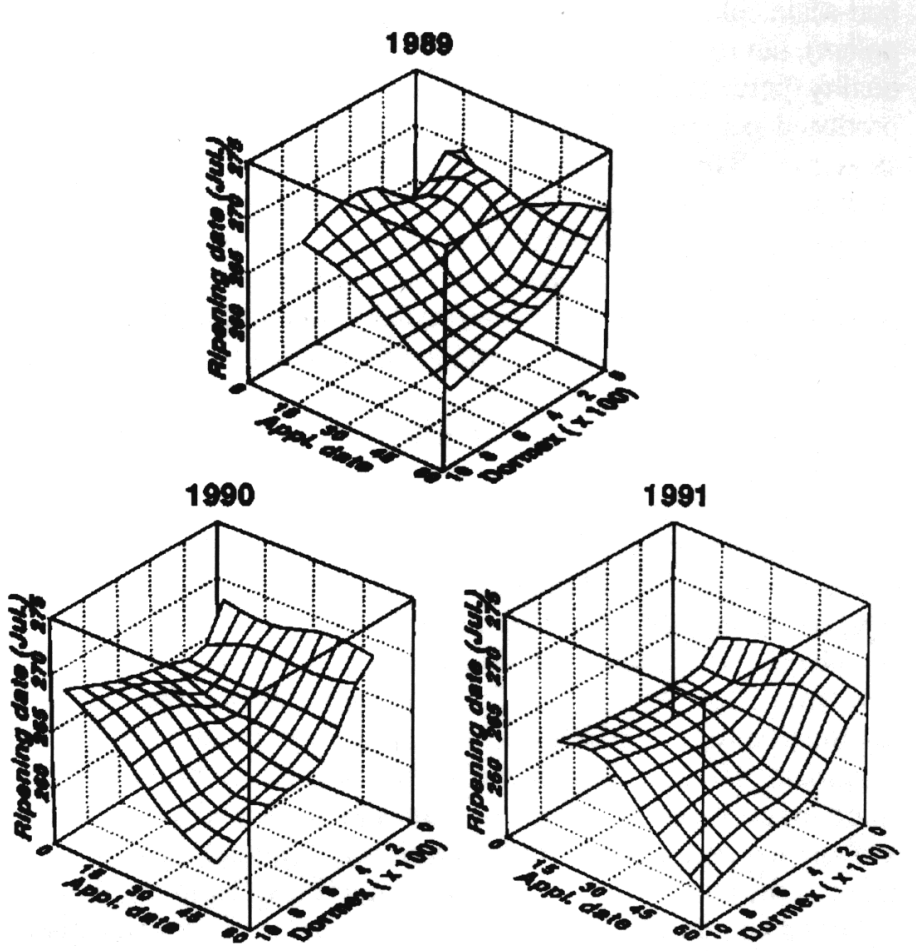

Fig. 5. Effect of hydrogen cyanamide (Dormex) on the advancement of shuck dehiscence (fruit ripening) of young 'Cheyenne' pecan trees. Results are over three growing seasons (1989-91) and the response surface is derived from best-fit spline curves of the intercepts of linear regression equations of the cumulative shuck dehiscence response. The best-fit polynomial regression equations (where $y=$ Julian date of budbreak and $x=m M$ rate of hydrogen cyanamide) for the earliest prebudbreak treatment date are as follows: for 1989, at -60 days, $y=a+$ $\mathrm{b}+\mathrm{cx}^{2}, r^{2}=0.96, \mathrm{a}=270, \mathrm{~b}=(-0.16), \mathrm{c}=7.5^{\mathrm{c}-6}$; for 1990, at -48 days, $\mathrm{y}=\mathrm{a}+$ $\mathrm{bx}+\mathrm{cx}^{2}, r^{2}=0.96, \mathrm{a}=268, \mathrm{~b}=(-0.02), \mathrm{c}=1.2^{\mathrm{e}-5} ;$ for 1991, at -59 days, $\mathrm{y}=\mathrm{a}+$ $\mathrm{bx}+\mathrm{cx}^{2}, r^{2}=0.95, \mathrm{a}=267, \mathrm{~b}=(-0.024), \mathrm{c}=1.35^{\mathrm{e}-5}$. 
Table 2. Analysis of variance (ANOVA) for nut production and pecan quality of 'Cheyenne' trees treated with hydrogen cyanamide (Dormex). ${ }^{\mathrm{Z}}$

\begin{tabular}{|c|c|c|c|c|c|c|}
\hline \multirow[b]{2}{*}{ Effect } & \multicolumn{4}{|c|}{ Nut wt/tree $(\mathrm{kg})$} & \multirow[b]{2}{*}{$\begin{array}{c}\text { Kernel }^{\mathrm{y}} \\
(\%)\end{array}$} & \multirow[b]{2}{*}{$\begin{array}{l}\text { Nut vol } \\
\quad\left(\mathrm{cm}^{3}\right)\end{array}$} \\
\hline & $\mathrm{df}$ & $\begin{array}{l}\text { Mean } \\
\text { square }\end{array}$ & F & $P>\mathrm{F}$ & & \\
\hline \multicolumn{7}{|c|}{1989} \\
\hline Rate (R) & 4 & 0.358 & 0.86 & NS & NS & NS \\
\hline \multicolumn{7}{|l|}{ Application } \\
\hline date (AD) & 3 & 0.274 & 0.66 & NS & NS & NS \\
\hline $\mathrm{R} \times \mathrm{AD}$ & 9 & 0.314 & 0.75 & NS & NS & NS \\
\hline Error & 76 & 0.418 & --- & & & \\
\hline \multicolumn{7}{|c|}{1990} \\
\hline $\mathrm{R}$ & 4 & 4.10 & 3.22 & 0.0500 & NS & NS \\
\hline $\mathrm{AD}$ & 3 & 1.08 & 0.85 & NS & NS & NS \\
\hline $\mathrm{R} \times \mathrm{AD}$ & 9 & 0.64 & 0.50 & NS & NS & NS \\
\hline Error & 77 & 1.27 & --- & & & \\
\hline \multicolumn{7}{|c|}{1991} \\
\hline $\mathbf{R}$ & 4 & 0.74 & 0.85 & NS & NS & NS \\
\hline $\mathrm{AD}$ & 3 & 3.28 & 4.15 & 0.0100 & NS & NS \\
\hline $\mathrm{R} \times \mathrm{AD}$ & 9 & 0.67 & 0.77 & NS & NS & NS \\
\hline Error & 75 & 0.87 & --- & & & \\
\hline
\end{tabular}

${ }^{\mathrm{z}}$ Dormant pecan trees were treated with hydrogen cyanamide (at $0,120,240,480$, and $960 \mathrm{~mm}$ ) at $\approx 60,45,30$, and 15 days before anticipated budbreak (1 Apr.).

${ }^{y}$ ANOVA for kernel and nut volume not included since there were no treatment effects.

${ }^{\mathrm{NS}}$ Nonsignificant.

\section{Discussion}

Prebudbreak hydrogen cyanamide applications substantially advanced pecan budbreak, flowering, and nut ripening without apparent side-effects. Effective concentrations and application dates were comparable to those reported for other deciduous crops. The observed ability of hydrogen cyanamide to induce early budbreak, even when applied in late autumn, is evidence that hydrogen cyanamide can at least partially substitute for chilling.

As observed with several other crops (Pontikis, 1989; Snir, 1988; Snir and Erez, 1988), a single application of hydrogen cyanamide is sufficient for advancing pecan budbreak; therefore, application costs are confined to one treatment. The observation in kiwi that older branches are substantially less sensitive than younger branches or vines (Linsley-Noakes, 1989) does not seem to be true for pecan, in that phenology of 80- and 7-year-old pecan trees treated with $960 \mathrm{~mm}$ hydrogen cyanamide was similar. Pecan trees in this study were not damaged unless treated with excessively high levels (>1920 mM) of hydrogen cyanamide; the lower effective concentrations did not have residual effects.

Budbreak was influenced by weather, in spite of hydrogen cyanamide treatments. For example, trees growing in the winter of 1989-90 were exposed to much more January cold, or chill hours $(\leq 7 \mathrm{C})$, than in the previous or subsequent winter and to warm temperatures during late winter; thus, budbreak was much earlier than normal. The time of budbreak is determined primarily by natural conditions. Hydrogen cyanamide partially substitutes for natural chilling. The chemical does not seem to be harmful under such conditions.

Hydrogen cyanamide reportedly increased budbreak of lateral buds in fig (Ficus carica L.) and raspberries (Erez, 1987); how- ever, this was not observed in pecan, perhaps because most lateral buds normally break anyway (and later abort) on pecan shoots (Wood, 1989). The normal postpollenation abscission of most of the lateral pecan shoots (Wood, 1989) seemed to be unaffected by hydrogen cyanamide.

This study indicates that hydrogen cyanamide can overcome phenology-related problems of pecan. First, since it partially satisfies chilling requirements, it can be used to compress budbreak, flowering, and fruit ripening in mild climates where low chilling may be a problem. Hydrogen cyanamide also can be used to synchronize flowering in orchards where the complement\&y of cultivars needs improvement. Similarly, it can be used in breeding efforts to adjust the availability of pollen; for example, to increase the feasibility of crossing two protogynous genotypes by treating one with hydrogen cyanamide.

The primary benefit of hydrogen cyanamide should be as a means to achieve early harvest without diminishing the trees' potential for producing a crop the following year, which is the problem with using ethephon as an early-harvest aid (Wood, 1988). Such a method should allow growers to take advantage of the benefits of early harvest.

\section{Literature Cited}

Erez, A. 1987. Chemical control of budbreak. HortScience 22:12401243.

George, A.P. and R.J. Nissen. 1988. Chemical methods on breaking dormancy of low chill nectarines: Preliminary evaluations in subtropical Queensland. Austral. J. Expt. Agr. 28:425-429.

George, A.P., R.J. Nissen, and J.A. Baker. 1988. Effects of hydrogen cyanamide in manipulating budburst and advancing fruit maturity of table grapes in southeastern Queensland. Austral. J. Expt. Agr. 28:533538.

Gumpertz, M. and S.G. Pantula. 1989. A simple approach to inference in random coefficient models. Amer. Statistician 43(4):203-210.

Linsley-Noakes, G.C. 1989. Improving flowering of kiwi fruit in climatically marginal areas using hydrogen cyanamide. Scientia Hort. 38:247259.

Marquard, R.D. 1988. Gutcrossing rates in pecan and the potential for increased yields. J. Amer. Soc. Hort. Sci. 113:84-88.

Mizelle, W.O. and G. Westberry. 1985. Early harvest-Will it pay? Proc. Georgia Pecan Growers Assn. 16:28-35.

Pontikis, C.A. 1989. Effects of hydrogen cyanamide on bloom advancement in female pistachio (P. vera L.). Fruit Var. J. 43(3):125-128.

Snir, I. 1983. Chemical dormancy breaking of red raspberry. HortScience 18:710-713.

Snir, I. 1988. Effects of hydrogen cyanamide on bud break in red raspberry. Scientia Hort. 34:75-83.

Snir, I. and A. Erez. 1988. Bloom advancement in sweet cherry by hydrogen cyanamide. Fruit Var. J. 42(4):120-122.

Shulman, Y., G. Nir, and S. Lavee. 1986. Oxidative processes in bud dormancy and the use of hydrogen cyanamide in breaking dormancy. Acta Hort. 179:141-148.

Wood, B.W. 1988. Ethephon and NAA facilitate early harvesting of pecans. J. Amer. Soc. Hort. Sci. 114:279-282.

Wood, B. W. 1989. Axillary shoot abscission in pecan and its relationship to growth regulators. J. Amer. Soc. Hort. Sci. 113:713-717.

Wood, B.W. and R.D. Marquard. 1992. Estimate of self-pollination in pecan orchards in the southeastern United States. HortScience 27:406 408.

Wood, B. W. , J.A. Payne, and L.J. Grauke. 1990. The rise of the U.S. pecan industry. HortScience 25:595,721-723.

Zelleke. A. and M. Kliewer. 1989. The effects of hydrogen cyanamide on enhancing the time and amount of budbreak in young grape vineyards. Amer. J. Enol. Viticult. 40(1):47-51. 